\title{
Biology of umbilical cord blood progenitors in bone marrow niches
}

\author{
Mo A. Dao, ${ }^{1,2}$ Michael H. Creer, ${ }^{3}$ Jan A. Nolta, ${ }^{2}$ and Catherine M. Verfaillie ${ }^{1,4}$ \\ ${ }^{1}$ Stem Cell Institute, University of Minnesota Medical School, Minneapolis; ${ }^{2}$ Department of Internal Medicine, Division of Oncology, Hematopoietic Development \\ and Malignancy Program, Washington University School of Medicine, St Louis, MO; ${ }^{3}$ Departments of Pathology and Laboratory Medicine, Saint Louis University \\ School of Medicine, St Louis, MO; ${ }^{4}$ Stamcel Instituut Leuven, Katholieke Universiteit Leuven, Belgium
}

\begin{abstract}
Within the bone marrow (BM), hematopoietic progenitor cells (HPCs) are localized in poorly oxygenated niches where they interact with the surrounding osteoblasts (OBs) through VLA4/VCAM-1 engagement, and are exposed to interleukin-6 (IL-6), stem cell factor (SCF), and chemokines such as CXCL12 (OB factors). Umbilical cord (UC) is more highly oxygenated that the $\mathrm{BM}$ microenvironment. When UC-HPCs are exposed to the $2 \%$ to $3 \% \mathrm{O}_{2}$ concentration found in the bone endosteum, their survival is significantly
\end{abstract}

decreased. However, engagement of VLA-4 integrins on UCB-derived CD34+ cells reduced cell death in $2 \%$ to $3 \% \mathrm{O}_{2}$ conditions, which was associated with an increase in phospho-Ser473 AKT and an increase in phospho-Ser9 GSK3b. Consistent with the role of GSK3b in destabilizing beta-catenin, there was more cytoplasmic beta-catenin in UC-HPCs exposed to $2 \%$ to $3 \% \mathrm{O}_{2}$ on fibronectin, compared with suspension culture. UC-HPCs cultured at $2 \%$ to $3 \% \mathrm{O}_{2}$ with $\mathrm{OB}$ factors showed an increase in nuclear beta- catenin and persistence of a small pool of CD34+38- HPCs. CFU assays followed by surface phenotyping of the plated colonies showed improved maintenance of mixed lineage colonies with both erythroid and megakaryocytic precursors. These studies provide a biologic perspective for how UC-derived HPCs adapt to the bone endosteum, which is low in oxygen and densely populated by osteoblasts. (Blood. 2007;110:74-81)

() 2007 by The American Society of Hematology

\section{Introduction}

The bone marrow (BM) endosteum has been identified as the primary niche for primitive hematopoietic progenitor cells (p-HPCs), while the BM microvascular region serves as the site for committed HPCs (c-HPCs). ${ }^{1-5}$ A longitudinal cross section of the bone shows that the endosteum is the farthest site from the bone vasculature. Consistent with this observation, the endosteum has the lowest oxygen pressure, compared with other regions within the bone. ${ }^{6}$ It was therefore concluded that low oxygen plays a role in the maintenance of p-HPCs. Consistent with this notion, when p-HPCs are cultured under low oxygen conditions, they retain their full multilineage engraftment potential when transplanted into an irradiated recipient. ${ }^{7}$ At the molecular level, the mechanisms by which low oxygen mitigates this effect are not fully understood, and to further delineate it was a major aim of the current study.

Another important feature of the endosteum is its mesenchymal composition. ${ }^{8}$ Compared with other regions of the bone, the endosteum has the highest number of osteoblasts, which play a role in the maintenance of p-HPCs. ${ }^{9,10}$ Manipulation of osteoblast development in vivo directly affects the size of the p-HPC population. ${ }^{11,12}$ Both adhesion molecules ${ }^{13}$ and soluble factors ${ }^{14,15}$ expressed by osteoblasts are important regulators of p-HPCs. These studies collectively suggest that $2 \%$ to $3 \%$ oxygen and osteoblast-derived factors play critical roles in p-HPC maintenance.

Although it is not surprising that BM-derived p-HPCs are better maintained under low oxygen, which is a natural feature within the endosteum, it is somewhat surprising that similar observations were noted with UCB-derived p-HPCs. Compared with the endosteum, the fetal blood environment is significantly higher in oxygen saturation, ${ }^{16}$ and obviously devoid of osteoblasts. To understand how UCB-derived p-HPCs survive and maintain their multilineage potential in an environment distinctly different from their natural origin, we examined the effect of conditions that recapitulate the in vivo endosteal microenvironment $-2 \% \mathrm{O}_{2}$, adhesion counterparts for VLA-4 and VLA-5 integrins, and osteoblast-derived cytokines and chemokines-on UCB p-HPC behavior. The results of our study show that intracellular events triggered by $2 \%$ to $3 \% \mathrm{O}_{2}$, integrin engagement, and osteoblast-derived factors culminate in the accumulation and nuclear translocation of beta-catenin in UCBderived $\mathrm{CD}_{3} 4^{+}$progenitors, which is associated with improved survival under hypoxic conditions.

\section{Materials and methods}

\section{Antibodies}

The following antibodies were purchased from Santa Cruz Biotech (Santa Cruz, CA): anti- $\alpha$-tubulin (monoclonal), antilaminin (monoclonal), antibeta-catenin (polyclonal), anti-GSK3 $\beta$ (polyclonal), anti-phosphor-Tyr216 GSK3 $\beta$ (polyclonal), anti-phospho-Ser9 GSK3 $\beta$ (monoclonal), and antiAKT (polyclonal). The antibody against phospho-Ser473-AKT (polyclonal) was purchased from Cell Signaling Technology (Danvers, MA) and the antibody against HIF-1 $\alpha$ (monoclonal) was purchased from Upstate Biotechnology (Lake Placid, NY). Secondary antirabbit HRP- and antimouse HRP-conjugated antibodies were all obtained from Amersham (Arlington Heights, IL). All human cytokines were purchased from R\&D
Submitted August 2, 2006; accepted January 23, 2007. Prepublished online as Blood First Edition paper, March 19, 2007; DOI 10.1182/blood-2006-08034447.

The publication costs of this article were defrayed in part by page charge payment. Therefore, and solely to indicate this fact, this article is hereby marked "advertisement" in accordance with 18 USC section 1734. 
Systems (Minneapolis, MN). All antibodies for flow cytometry were obtained from BD Pharmingen (San Diego, CA).

\section{Primary CD34+ cell culture and manipulation in $2 \%$ to $3 \%$ versus $20 \%$ oxygen}

UCB was obtained from the Cardinal Glennon Umbilical Cord Blood Bank, St Louis, MO, under the approved protocol of the human Subjects Committee of Washington University School of Medicine. Mononuclear cells were isolated by layering on equal volume of Ficoll-Hypaque Amersham Bioscience (Uppsala, Sweden) prior to centrifugation. $\mathrm{CD} 34^{+}$cell enrichment from the mononuclear buffy coat was performed using a $\mathrm{CD}_{3} 4^{+}$isolation kit and immunomagnetic column separation techniques as specified by the manufacturer (Miltenyi Biotec, Sunnyvale, CA). On average, a purity of more than $95 \% \mathrm{CD} 34^{+}$cells was obtained after 2 column passages, as assessed by fluorescence-activated cell sorter (FACS) analysis.

\section{Cell culture}

$\mathrm{CD}_{3}{ }^{+}$cells were washed twice in $\mathrm{PBS} / 1 \%$ fetal calf serum (FCS; Atlanta Biologicals, Lawrenceville, GA) prior to culture in $2 \%$ to $3 \%$ versus 20\% oxygen. BIT-9500 culture medium (Stem Cell Technologies, Vancouver, BC) was supplemented with $40 \mathrm{mg} / \mathrm{mL}$ low-density lipoprotein (Sigma, St Louis, MO) and 2 different cytokine cocktails: (1) 100 $\mathrm{ng} / \mathrm{mL}$ stem cell factor (SCF), $25 \mathrm{ng} / \mathrm{mL}$ fetal liver tyrosine kinase 3 ligand (FLT3L), $25 \mathrm{ng} / \mathrm{mL}$ thrombopoietin (TPO), or (2) $100 \mathrm{ng} / \mathrm{mL}$ $\mathrm{SCF}, 50 \mathrm{ng} / \mathrm{mL}$ CXCL12, and $25 \mathrm{ng} / \mathrm{mL}$ IL-6 or leukemia inhibitory factor (LIF) (all cytokines were from R\&D Systems). Non-tissue culture-treated plates were coated with $0.01 \%$ poly-lysine (Sigma), $25 \mathrm{ng} / \mathrm{mL}$ recombinant fibronectin (FN) fragment CH-296 (Takara, Japan) in $1 \times$ PBS (Gibco BRL, Gaithersburg, MD), $10 \mu \mathrm{g} / \mathrm{mL}$ recombinant VCAM-1 (R\&D Systems) in sterile water, for 1 hour at room temperature and subsequently blocked with 3\% BSA (Sigma) in PBS for another hour. $\mathrm{CD} 34^{+}$cells were plated on PLL-coated versus VCAM-1-coated versus FN-coated plates incubated for 30 minutes at $20 \% \mathrm{O}_{2}$ to allow attachment. For coculture with the osteoblasts cell line MG-63 cells (ATCC, Manassas, VA), cells were plated in DMEM/20\% FCS for 24 hours, and the adherent monolayer of MG-63 cells was rinsed twice with warm $1 \times$ PBS and re-fed with BIT-9500-cultured medium. Coculture experiments were performed in the absence of exogenous growth factors. All plates were then transferred to hypoxic biochambers (Stem Cell Technologies) and flushed with a premix gas consisting of $97 \% \mathrm{~N}_{2}$ according to the manufacturer's instruction. The chamber was then placed in a conventional $37^{\circ} \mathrm{C} / 5 \% \mathrm{CO}_{2}$ incubator. A second gas flushing was performed 6 hours later, and cells were left in hypoxic conditions for the duration of the culture period. For all cultures longer than 72 hours, medium with fresh cytokines was changed every 72 hours and the chamber was reflushed.

For the integrin preactivation experiments, UCB-derived CD $34^{+}$ cells were prestimulated for 4 hours in BIT-9500 medium supplemented with $40 \mu \mathrm{g} / \mathrm{mL}$ low-density lipoprotein, $100 \mathrm{ng} / \mathrm{mL} \mathrm{SCF}$, and $50 \mathrm{ng} / \mathrm{mL}$ TPO. Cells were then washed twice with warm PBS (Hyclone, Logan, UT) and resuspended in the appropriate culture medium prior to plating on precoated plates. Clonogenic progenitor assessment was measured by plating $10^{5}$ cultured cells in methylcellulose media supplemented with cytokines (Stem Cell Technologies). After 12 to 14 days at $37^{\circ} \mathrm{C}$ in $5 \%$ $\mathrm{CO}_{2}$, colonies were scored.

\section{Annexin V staining}

After culture, cells were washed twice with cold PBS and resuspended in $1 \times$ binding buffer (0.01 M HEPES, $\mathrm{pH} 7.4 ; 0.14 \mathrm{M} \mathrm{NaCl} ; 2.5 \mathrm{mM} \mathrm{CaCl}_{2}$; all from Sigma) and stained with $4 \mu \mathrm{L}$ annexin V (BD Biosciences, San Diego, CA) and $2 \mu \mathrm{L}$ 7-AAD or propidium iodide (Sigma). After incubating at room temperature for 15 minutes, cells were diluted 1:4 with $1 \times$ binding buffer and evaluated using the FACSCalibur (Becton Dickinson, Franklin Lakes, NJ).

\section{Cell cycle and division kinetics}

To determine the percentage of cells in $\mathrm{G}_{0}$ at the end of the culture, cells were fixed in $2 \%$ to $3 \%$ formaldehyde at room temperature for 30 minutes and permeabilized with saponin (Sigma). Cells were then washed twice with $\mathrm{PBS} / 2 \%$ FCS containing saponin and $5 \mu \mathrm{L}$ Ki67-PE antibody (BD Biosciences) was added per million cells. After one hour of staining in the dark, cells were washed twice and analyzed on a FACSCalibur. To measure cell division kinetics, freshly isolated $\mathrm{CD} 34^{+}$cells were stained with CFSE (Sigma) at 1:2000 dilution in a 1-mL final volume for 3 minutes at room temperature. FCS $(400 \mu \mathrm{L})$ was added to quench the reaction for one minute. Cells were washed 3 times in $13 \mathrm{~mL} 1 \times \mathrm{PBS} / 2 \% \mathrm{FCS}$ and once in $5 \mathrm{~mL}$ BIT-9500-cultured medium prior to plating at $2 \%$ to $3 \% \mathrm{O}_{2}$ or $20 \%$ $\mathrm{O}_{2}$ on FN- or PLL-coated plates. Analysis was performed using the FL1-channel on the FACSCalibur.

\section{Subcellular fractionation and Western blotting}

Cultured hematopoietic cells were collected by cell dissociation buffer (Gibco BRL/Invitrogen, Carlsbad, CA) and cell counts were normalized after counting with trypan blue to exclude dead cells. On average, we used $10^{6}$ live cells for each subcellular fractionation. After washing in ice-cold PBS, cells were washed once in ice-cold hypotonic buffer (50 mM Hepes, $10 \mathrm{mM} \mathrm{NaCl}, 1 \mathrm{mM}$ DTT; all from Sigma), and spun at $800 \mathrm{~g}$ at $4^{\circ} \mathrm{C}$ for 15 minutes. Cells were resuspended in hypotonic buffer and protease inhibitor tablets (Roche Diagnostics, Mannheim, Germany) at $2 \times$ per cell volume $\left(\sim 50 \mu \mathrm{L} / 10^{6}\right.$ cells $)$ and allowed to swell for 10 minutes on ice, followed by 10 strokes in precooled homogenizer with pestle B. Samples were then spun at $2000 \mathrm{rpm}$ at $4^{\circ} \mathrm{C}$ for 15 minutes to collect the nuclei. The supernatant (cytosolic fraction) was transferred to a cold microcentrifuge tube. The nuclear pellets were rinsed 3 times with hypotonic buffer. Nuclei were resuspended in ice-cold hypertonic buffer (50 mM Hepes, $400 \mathrm{mM} \mathrm{NaCl}, 1 \mathrm{mM}$ DTT, $0.5 \% \mathrm{NP}-40)$ and protease inhibitor tablets and sonicated on ice with 3 pulses of 2 seconds each. Samples were then centrifuged at $14000 \mathrm{rpm}$ at $4^{\circ} \mathrm{C}$ for 15 minutes, and supernatant (corresponding to nuclear proteins) was transferred to a new ice-cold microcentrifuge tube. An equal volume of $2 \times$ sample buffer ( $2 \%$ SDS, $10 \%$ glycerol, 0.96 M 2-mercaptoethanol, 0.3 M Tris; pH 6.8; all from Sigma), and 0.02\% bromophenol blue (BioRad, Hercules, CA) was added and samples were boiled for 5 minutes. Samples were separated on $8 \%$ sodium dodecyl sulfatepolyacrylamide gel electrophoresis (SDS-PAGE) gels for HIF- $1 \alpha$, beta-catenin, AKT, MAPK, tubulin, lamin, and GSK3 $\beta$. Gels were transferred to Immuno-Blot PVDF membrane (BioRad) overnight for beta-catenin or 2 hours for all the other proteins. Membranes were blocked using $3 \%$ or $5 \%$ nonfat dry milk in PBS-T $(\mathrm{pH} 7.6$, $0.1 \%$ Tween-20 in PBS) for 1 hour at room temperature and incubated for 1 hour or overnight with specific primary antibodies. Blots were then washed 3 times for 5 minutes with PBS-T, and incubated with secondary antibodies in 5\% nonfat milk at a 1:10 000 dilution for monoclonal antibodies, 1:20 000 for polyclonal antibodies, or according the manufacturer's protocol. Immunoreactive bands were visualized using secondary horseradish peroxidase-conjugated Abs and chemiluminescence (Amersham).

\section{Statistics}

Statistical analyses were performed on Excel using Student $t$ test.

\section{Results}

\section{Integrin engagement on fibronectin reduces cell death of UCB-HPCs exposed to $2 \%$ to $3 \%$ oxygen.}

Fetal blood is more oxygenated $\left(\sim 5 \% \mathrm{O}_{2}\right)$ compared with the bone endosteum $(>2 \%) .{ }^{16,17}$ It is therefore not surprising that Ivanovic et $\mathrm{al}^{18}$ and Hermitte et a ${ }^{19}$ observed more cell death in UCB-HPCs cultured at $2 \%$ to $3 \% \mathrm{O}_{2}$ than at $20 \% \mathrm{O}_{2}$. Of interest, 
however, studies have shown that UCB-HPCs injected intrafemorally into immunodeficient mice efficiently engraft in primary and secondary recipients. ${ }^{20}$ This suggests that there may be factors produced by osteoblasts within the endosteum that support the survival and multilineage potential of UCB-HPCs, under hypoxic conditions. Jung et al reported that the interaction between osteoblasts and HPCs enhances cell survival of HPCs. ${ }^{13}$ Here, we hypothesize that the interaction between VCAM-1 and/or fibronectin, expressed and/or secreted by osteoblasts, and the VLA-4 integrin, expressed on HPCs, may provide a prosurvival signal for UCB-HPCs exposed to low $\mathrm{O}_{2}$. To test this, we plated freshly isolated UCB-CD34+ ${ }^{+}$progenitors onto poly-lysine (PLL)-, VCAM-1-, or fibronectin (FN)-coated plates in the presence of a cytokine cocktail (SCF + FLT3L + TPO), shown previously to be optimal for HPC cultures ${ }^{21}$; the plates were then immediately placed in a $20 \%$ (Figure 1A left) or $2 \%$ to $3 \%$ (Figure $1 \mathrm{~A}$ middle) $\mathrm{O}_{2}$ environment, and cell death was assessed after 48 hours. Compared with $20 \% \mathrm{O}_{2}$ culture, we observed a more than 2 -fold increase in cell death in $2 \%$ to $3 \%$ $\mathrm{O}_{2}$ culture. Surprisingly, we saw no attenuation of cell death when $\mathrm{UCB}_{-\mathrm{CD}} 34^{+}$cells were cultured at $2 \%$ to $3 \% \mathrm{O}_{2}$ on VCAM-1- or FN-coated plates.

The fact that adhesion to fibronectin did not lead to improved survival led us to investigate the following possibilities. First, hypoxia may suppress the surface expression of VLA-4 integrins. However, we saw no differences in the levels of VLA-4 integrin on $\mathrm{UCB}^{-C D} 34^{+}$cells at $20 \%$ or $2 \%$ to $3 \% \mathrm{O}_{2}$ by FACS (data not shown). Alternatively, hypoxia may interfere with the activation of VLA-4 integrins. To address this hypothesis, we pretreated UCB$\mathrm{CD} 4^{+}$progenitors with $100 \mathrm{ng} / \mathrm{mL} \mathrm{SCF}+\mathrm{TPO}$ to activate the integrins, ${ }^{22}$ prior to exposure to $2 \%$ to $3 \% \mathrm{O}_{2}$ for 48 hour. We observed a significant reduction in cell death when UCB-CD34+ cells were preactivated with these cytokines prior to $2 \%$ to $3 \% \mathrm{O}_{2}$

A

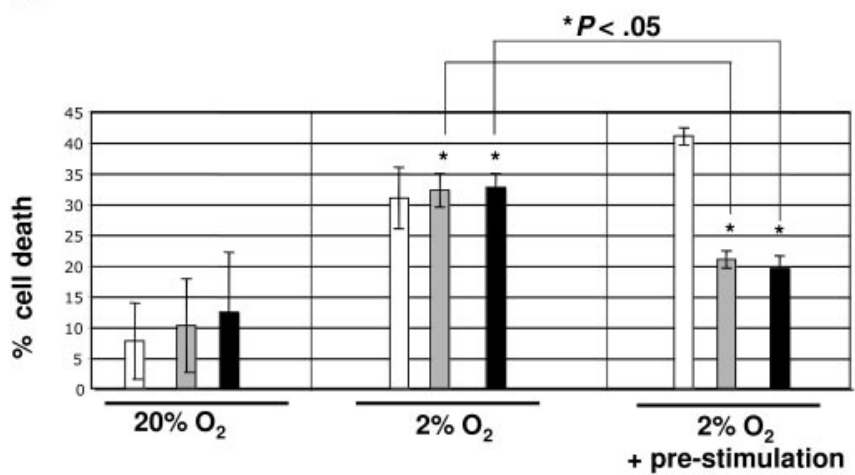

culture on VCAM-1- or FN-coated plates; this preactivation step did not attenuate cell death of UCB-CD34+ ${ }^{+}$cells plated on PLL plates at $2 \%$ to $3 \% \mathrm{O}_{2}$ (Figure $1 \mathrm{~A}$ right panel). Of note, in these studies, we used a recombinant fibronectin fragment, $\mathrm{CH}-296$, which includes the CS-1 domain and the RGD domain as binding sites for VLA-4 and VLA-5 integrins, both of which are expressed on HPCs. We did not see a further reduction of cell death on FN, compared with VCAM-1, suggesting that VLA-4 engagement alone was sufficient for the prosurvival effect under $2 \%$ to $3 \% \mathrm{O}_{2}$. We used fibronectin $(\mathrm{FN})^{21}$ as the ligand throughout the remaining part of the current studies.

To explore the biologic mechanism for this prosurvival effect mediated by integrins in $2 \%$ to $3 \% \mathrm{O}_{2}$ culture, we assessed the phosphorylation state of AKT and MAPK, 2 signaling molecules commonly activated downstream of integrin engagement and implicated in cell survival. ${ }^{23,24}$ We found that in $20 \% \mathrm{O}_{2}$ culture, AKT phosphorylation on Ser473 was detected at equal levels between UCB progenitors cultured on PLL- and on FN-coated plates (Figure 1B). However, in $2 \%$ to $3 \% \quad \mathrm{O}_{2}$ culture, this phosphorylation was detectable only in cells maintained on FNcoated plates and not on PLL-coated plates. This observation is consistent with the reduced cell death when cells were maintained on FN. In contrast, we did not detect phosphorylated MAPK, in cells cultured on either PLL- or FN-coated plates at $2 \%$ to $3 \% \mathrm{O}_{2}$ (Figure 1B). Consistent with the absence of MAPK activation, which is important for cell proliferation, ${ }^{25}$ more cells were in $\mathrm{G}_{0}$ (Ki-67 negative) when cultured at $2 \%$ to $3 \% \mathrm{O}_{2}$ compared with $20 \% \mathrm{O}_{2}$, and CFSE-labeling studies demonstrated that cells maintained at $2 \%$ to $3 \% \mathrm{O}_{2}$ had undergone significantly fewer cell divisions than when maintained at $20 \% \mathrm{O}_{2}$ (Figure 1C), consistent with previous reports. ${ }^{19}$ Thus, engagement of integrins on cells placed under hypoxic conditions results in phosphorylation of

B

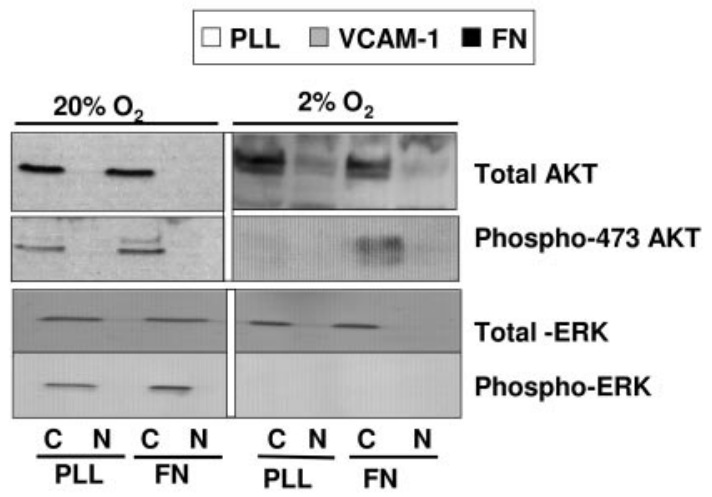

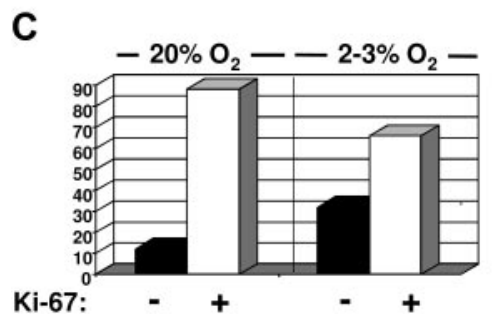
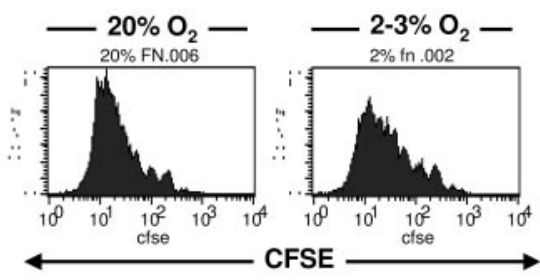

Figure 1. Assessment of cell death and proliferation of UCB-derived CD34+ cells cultured in the presence of SCF, FLT3L, TPO in $2 \%$ to $3 \%$ versus $20 \% \mathrm{O}_{2}$. (A) Freshly isolated CD $34^{+}$progenitors were either plated directly (left and middle) or prestimulated with SCF + TPO for 2 to 4 hours (right) prior to plating on non-tissue culture-treated plates coated with PLL (white bar), or VCAM-1 (gray bar), or FN (black bar). Annexin V/PI staining was done on cultured cells after 48 hours of culture. A total of 4 to 5 separate cord blood samples was used for each experiment and statistics were done using Student $t$ test. ${ }^{*} P<.05$. (B) Total protein levels and phosphorylated AKT and MAPK were assessed by immunoblotting from lysates for cells cultured in $20 \%$ (left) versus $2 \%$ to $3 \%$ (right) $\mathrm{O}_{2}$ on PLL- versus $\mathrm{FN}$-coated plates for 48 hours. (C) CD $34{ }^{+}$progenitors harvested after culture in $20 \%$ and $2 \%$ to $3 \% \mathrm{O}_{2}$ on fibronectin were stained with $\mathrm{Ki}-67$ antibody to assess the percentage of cells that was in $\mathrm{G}_{0}$ (left). FACS analysis of CFSE-labeled CD34 ${ }^{+}$cells after culture for 7 days on fibronectin in $20 \%$ and $2 \%$ to $3 \% \mathrm{O}_{2}$ to measure cell division kinetics. 
AKT, which is associated with enhanced survival of UCB-HPCs maintained at $2 \%$ to $3 \% \mathrm{O}_{2}$.

\section{GSK3//beta-catenin signaling cascade in UCB-CD34+ progenitors is modulated by integrin engagement and osteoblast-derived factors at $2 \%$ to $3 \% \mathrm{O}_{2}$}

One of the downstream targets of AKT is GSK3 $\beta$, a serine threonine kinase that becomes inactivated by AKT-mediated phosphorylation on Ser9. ${ }^{26,27}$ GSK3 $\beta$ activity has been directly correlated to the degradation of beta-catenin..$^{28,29}$ Forced expression of beta-catenin enhances stem cell activity, ${ }^{30,31}$ and a recent study has suggested that in vivo administration of a GSK3 $\beta$ inhibitor enhances recovery of HPCs with transplantation/engraftment potential, ${ }^{32}$ further highlighting the GSK3 $\beta /$ beta-catenin axis as a prominent signaling cascade in the fate of HPCs. As we observed AKT phosphorylation in $\mathrm{UCB}-\mathrm{CD} 34^{+}$progenitors on $\mathrm{FN}$ in $2 \%$ to $3 \% \mathrm{O}_{2}$, we hypothesized that GSK3 $\beta$ Ser9 phosphorylation and levels of beta-catenin may both be differentially regulated by integrin engagement. We compared the phosphorylation of GSK3 $\beta$ on Ser9 versus Tyr-216 (identified as a site that enhances its activity $)^{33}$ in cells plated on FN or PLL, in a $2 \%$ to $3 \% \mathrm{O}_{2}$ environment (Figure 2A). Compared with cells plated on PLL, we detected more Ser9 phosphorylated GSK3 $\beta$ in cells plated on FN, consistent with the higher AKT phosphorylation. Although the levels of Ser9 phospho-GSK3 $\beta$ were higher in response to integrin engagement, the levels of Tyr-216 phospho-GSK3 $\beta$ and the total amount of GSK3 $\beta$ protein were identical whether integrins were engaged or not. Consistent with the higher degree of phospho-Ser9GSK3 $\beta$, we observed a small but detectably higher amount of beta-catenin in UCB-CD34+ cells cultured on FN. However, beta-catenin was predominantly cytoplasmic under these conditions. Levels of HIF-1 $\alpha$, a hypoxia-inducible factor, were similar in cells plated in $2 \%$ to $3 \%$ oxygen on PLL- or FN-coated plates (Figure 2B). HIF-1 $\alpha$ protein was not detectable at $20 \%$ oxygen (data not shown). These observations suggest that in $2 \%$ to $3 \%$ oxygen, integrin engagement exerts a specific effect on AKT, GSK3 $\beta$, and beta-catenin and that this effect was likely not due to differential sensitivity to low oxygen as nuclear HIF- $1 \alpha$ did not differ between cells on PLL- or on FN-coated plates.

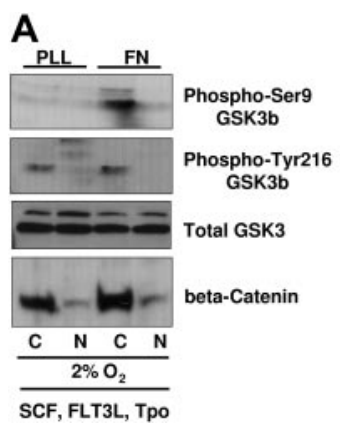

B

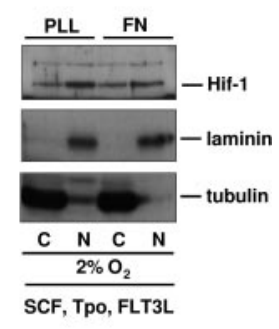

Figure 2. GSK3ß/beta-catenin phosphorylation and levels in UCB-derived CD $34^{+}$cells cultured in $2 \%$ to $3 \% \mathrm{O}_{2}$ on PLL- versus $\mathrm{FN}-$ coated plates. (A) Integrin-preactivated $\mathrm{CD} 34^{+}$progenitors from different cord blood donors were pooled and plated at 1 million cells per $3 \mathrm{~mL}$ medium containing SCF, FLT3L, TPO, on PLL- versus FN-coated plates for 48 hours at $2 \%$ to $3 \% \mathrm{O}_{2}$. Viable cell numbers were normalized by Trypan blue count and then subfractionated for protein analysis. Immunoblots were probed with antibodies against beta-catenin, phospho-Ser9-GSK3 $\beta$, phospho-Tyr216-GSK3 $\beta$. Blots were stripped and reprobed with GSK3 $\beta$ antibody. (B) Upper part of the blots (higher than $70 \mathrm{kDa}$ ) was immunoblotted with antibodies against HIF-1 alpha. All blots were reprobed with antibodies against laminin and tubulin, which served as nuclear and cytoplasmic control, respectively.

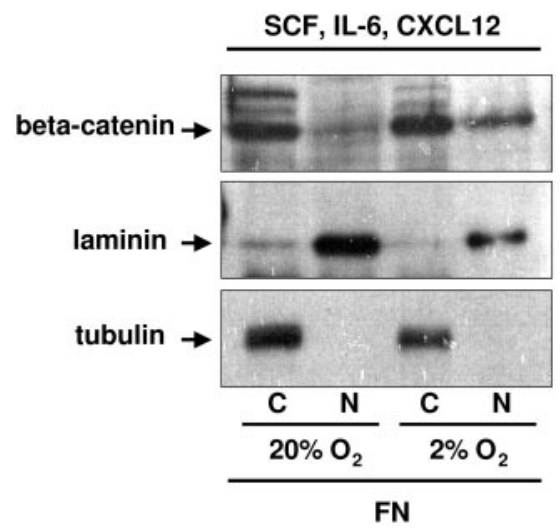

Figure 3. Nuclear beta-catenin detection in UCB-CD34+ progenitors exposed to $2 \%$ to $3 \% \mathrm{O}_{2}$ on PLL- versus $\mathrm{FN}$-coated plates in the presence of osteoblastderived cytokines and chemokine. CD34+ progenitors were cultured in SCF, IL-6, and CXCL12 for 48 hours on FN-coated plates in $2 \%$ to $3 \%$ versus $20 \% \mathrm{O}_{2}$. Cells were normalized by cell count with Trypan blue to exclude dead cells. An average of 2 to 3 million cultured cells was subfractionated for protein analyses in the presence of NEM or ubiquitin aldehyde enzyme, to preserve the ubiquitinated form of beta-catenin. Tubulin and laminin were used as cytoplasmic and nuclear control, respectively.

In studies described, the cytokine cocktail used consisted of SCF, FLT3L, and TPO. Although SCF is secreted by osteoblasts, ${ }^{34}$ FLT3L and TPO have not been reported to be produced by osteoblasts. To more closely mimic the BM hematopoietic stem cell (HSC) niche, we substituted FLT3L and TPO with IL-6 and CXCL12, both of which are secreted by osteoblasts and are known to influence p-HPCs. ${ }^{14,15,34,35}$ We again assessed the levels of cytoplasmic and nuclear beta-catenin in $\mathrm{UCB}^{-\mathrm{CD}} 34^{+}$cells plated on $\mathrm{FN}$ in $20 \%$ versus $2 \%$ to $3 \% \mathrm{O}_{2}$ in the presence of SCF + IL-6 + CXCL12 (OB factors). Although beta-catenin was readily detectable when either cytokine cocktail was used for cells cultured on $\mathrm{FN}$ in $2 \%$ to $3 \% \mathrm{O}_{2}$, significantly more nuclear beta-catenin was present when cells were cultured with OB factors (Figure 3). These observations suggest that integrin engagement by FN and HPC stimulation by $\mathrm{OB}$ factors collaborate in the enhanced detection of nuclear beta-catenin.

\section{Integrin engagement, $\mathrm{OB}$ factors, and hypoxia preserve primitive $\mathrm{CD} 34^{+} \mathrm{CD} 38^{-}$progenitors with multilineage myeloid differentiation potential}

To evaluate the functional repercussions of the integrin- and cytokine-mediated activation of AKT-GSK3 $\beta$-beta-catenin pathway, we determined whether more primitive HPCs were preserved when cells were plated on FN, in hypoxic conditions (Figure 4). One surface marker that is present on HPCs and not on differentiated hematopoietic cells is CD34. ${ }^{36,37}$ We first assessed the percentage of $\mathrm{CD}_{34}{ }^{+}$cells within cultures at $2 \%$ to $3 \% \mathrm{O}_{2}$ on PLLor $\mathrm{FN}$-coated plates versus cultures of $\mathrm{CD} 4^{+}$progenitors at $20 \%$ $\mathrm{O}_{2}$ on FN-coated plates, with as cytokine cocktail SCF, FLT3-L, and TPO. When we analyzed all cells (live and necrotic cells), we observed no significant differences between the percentage of $\mathrm{CD} 4^{+}$cells. However, when we gated exclusively on the live cells, we saw a higher percentage of $\mathrm{CD}_{3}{ }^{+}$cells in the $2 \%$ to $3 \%$ $\mathrm{O}_{2}$ culture than in the $20 \% \mathrm{O}_{2}$ culture. We noted more CD34 $4^{\mathrm{dim}}$ cells in cultures at $20 \% \mathrm{O}_{2}$ than in cultures at $2 \%$ to $3 \% \mathrm{O}_{2}$, suggesting that the more mature progenitors poorly tolerate the low oxygen ambiance. When comparing the cultures on PLL versus on $\mathrm{FN}$ at $2 \%$ to $3 \% \mathrm{O}_{2}$, we observed a similar percentage of $\mathrm{CD} 34^{+}$ cells; however, there were substantially more cells in cultures on 

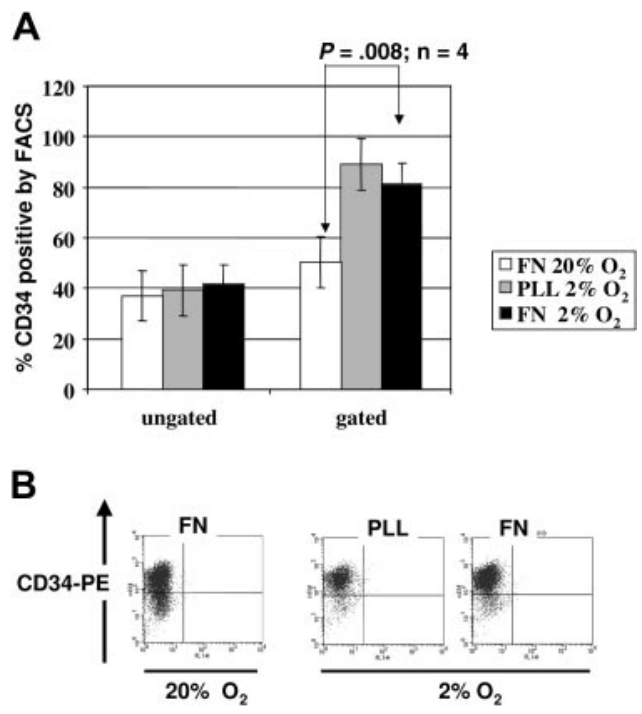

Figure 4. CD34 expression on UCB-derived CD34+ progenitors cultured in the presence of SCF, FLT3L, TPO in $2 \%$ to $3 \%$ versus $20 \% \mathrm{O}_{2}$. FACS staining for surface CD34 was performed on cells cultured for 48 hours in $2 \%$ to $3 \%$ versus $20 \%$ $\mathrm{O}_{2}$ on PLL- versus FN-coated plates. (A) Mean percentage of $\mathrm{CD}_{34}{ }^{+}$cells $\pm \mathrm{SEM}$ after culture at $20 \%$ on FN (white bar), $2 \%$ to $3 \%$ on PLL (gray bar), and $2 \%$ to $3 \%$ on FN (black bar) from 3 independent experiments based on ungated (left) versus gated on live cells (right). (B) We show a representative FACS analysis; analysis was gated on live cells only.

FN than on PLL, consistent with the higher cell death in the absence of integrin engagement. Thus, low oxygen appears not to promote expansion of $\mathrm{CD}_{3} 4^{+}$pool but loss of the $\mathrm{CD} 34^{\mathrm{dim}}$ committed mature progenitors.

As nuclear translocation of beta-catenin required that cells were not only cultured on FN but also in the presence of osteoblastderived cytokines, we next determined if more $\mathrm{CD} 34^{+} \mathrm{CD} 38^{-}$cells persisted in cultures supported with SCF, IL-6, and CXCL12 at 2\% to $3 \% \mathrm{O}_{2}$ or cultured with SCF, FLT3-L, and TPO at $2 \%$ to $3 \% \mathrm{O}_{2}$ (Figure 5A-B). We consistently detected significantly more $\mathrm{CD} 34{ }^{+} \mathrm{CD} 38^{-}$cells in UCB-HPC cultures at $2 \%$ to $3 \% \mathrm{O}_{2}$ with $\mathrm{SCF}+\mathrm{IL}-6+\mathrm{CXCL} 12$ on 7 day than in cultures maintained at $2 \%$ to $3 \% \mathrm{O}_{2}$ but with $\mathrm{SCF}$, Flt3-L, and TPO. We also cultured UCB-HPCs with a human osteoblast cell line, MG-63, previously reported to secrete SCF, IL-6, and SDF-1,38,39 an additional method to recapitulate the "bone marrow niche." Maintenance of $\mathrm{CD} 34^{+} \mathrm{CD} 38^{-}$cells in cultures on FN with SCF, IL-6, and CXCL12 versus cultures on the MG-63 monolayer at 2\% to $3 \% \mathrm{O}_{2}$ (Figure 5C) was similar. Thus, the combination of $\mathrm{OB}$ factors and hypoxia preserved the more primitive subfraction of $\mathrm{CD} 34^{+}$cells, consistent with our finding that significantly more beta-catenin could be detected in the nucleus under these conditions (Figure 3).

We next cultured UCB-CD $34^{+}$progenitors on FN-coated plates for 3 weeks in $2 \%$ to $3 \%$ versus $20 \% \mathrm{O}_{2}$ in the presence of OB factors and enumerated colony-forming units. As was seen in short-term cultures (Fig 5), significantly more CD $34^{+} \mathrm{CD} 38^{-}$ and $\mathrm{CD} 34^{+} \mathrm{CD} 133{ }^{+}$cells were present after the 3 -week culture in $2 \%$ to $3 \%$ than $20 \% \mathrm{O}_{2}$ cultures (Figure 6A). In addition, significantly more CFUs could be recovered from the $2 \%$ to $3 \%$ than $20 \% \quad \mathrm{O}_{2}$ cultures (Figure 6B, with in addition more CFU-Mix in the $2 \%$ to $3 \%$ than $20 \% \mathrm{O}_{2}$ cultures). Next, we used FACS to phenotype and confirm the presence of more CFU-Mix in $2 \%$ to $3 \%$ oxygen. We noted no differences in the proportion of granulocytes (CD15 and CD16), monocytes (CD14), or myeloid progenitors (CD33) (data not shown) between $2 \%$ to $3 \%$ and $20 \% \mathrm{O}_{2}$ cultures, but erythroid (GlycoA) and megakaryocytic (CD41 and CD61) cells were detectable only in the progeny of $\mathrm{UCB}^{-\mathrm{CD} 34^{+}}$progenitors cultured in $2 \%$ to $3 \% \mathrm{O}_{2}$, and not progenitors cultured in $20 \% \mathrm{O}_{2}$ (Figure 6C). These observations further confirm that hypoxia combined with $\mathrm{OB}$ factors contribute to the maintenance of multilineage myeloid potential of $\mathrm{UCB}-\mathrm{CD} 34^{+}$progenitors.

\section{Discussion}

The goal of the current studies was not to establish another ex vivo expansion culture for UCB-HPCs, but rather to address a fundamental biologic question: how do environmental factors in the BM of a preconditioned recipient affect the fate of the bone-engrafted UCB-HPCs? Under normal physiological conditions, the $\mathrm{O}_{2}$ concentration in the BM endosteum is approximately $2 \%,{ }^{17}$ whereas it is approximately $5 \%$ in UCB. ${ }^{16}$ Consistent with the notion that the fate of cells is determined in part by their microenvironment, ex vivo culture of $\mathrm{BM}$ progenitors and $\mathrm{CB}$ progenitors in $2 \%$ and $5 \%$ $\mathrm{O}_{2}$, respectively, has been reported to maintain and/or increase their severe combined immune deficiency (SCID) repopulating cells and/or CFU potential. ${ }^{40-42}$ When $\mathrm{CB}$ progenitors were cultured in $2 \% \mathrm{O}_{2}$, there was an increase in cell death. ${ }^{18,19}$ At the same time, xenotransplantation models of human UCB-HPCs into irradiated adult murine recipients show that these cells can lodge within the $\mathrm{BM}$ niches and give rise to all blood lineages. ${ }^{20}$ These studies suggest that UCB progenitors can adapt themselves to a nonnative environment, in this case, the adult BM.

\section{A}

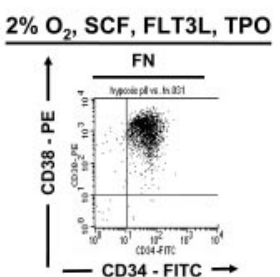

\section{B}

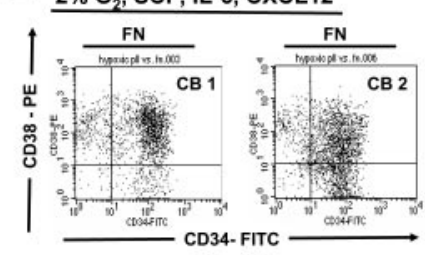

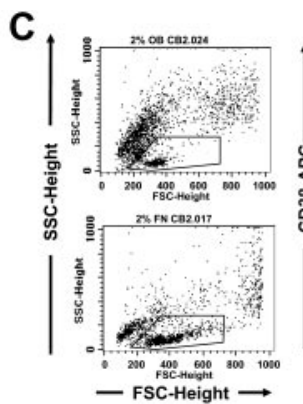

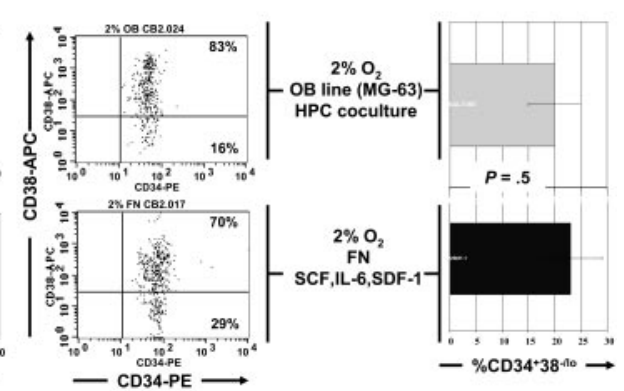

Figure 5. Similar preservation of $\mathrm{CD}_{3} 4^{+} \mathrm{CD} 38^{-}$cells when UCB progenitors are cultured at $2 \%$ to $3 \% \mathrm{O}_{2}$ on $\mathrm{FN}$ with $\mathrm{OB}$ factors or in contact with the osteoblast cell line MG-63. CD $34^{+}$progenitors were cultured in (A) SCF, FLT3L, and TPO or in (B) SCF, IL-6, and CXCL12. (C) CD $34^{+}$progenitors were cultured for 7 days at $2 \%$ to $3 \%$ O 2 either on FN-coated plates and SCF, IL-6, and CXCL2 or on the MG-63 osteoblast feeder. FACS analysis was done on CD45 ${ }^{+}$gated fractions in the coculture. Shown here is a FACS plot representative of 1 of 3 independent experiments. 
A
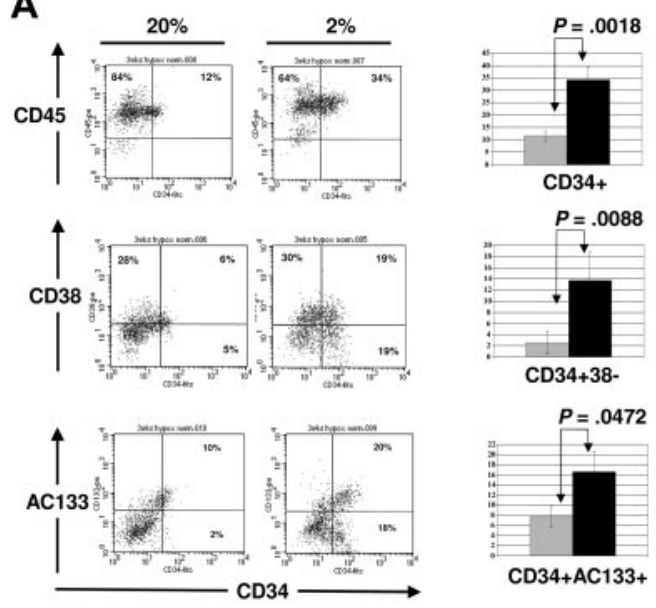

$\square 20 \% \mathrm{O}_{2}$ $2 \% \mathrm{O}_{2}$

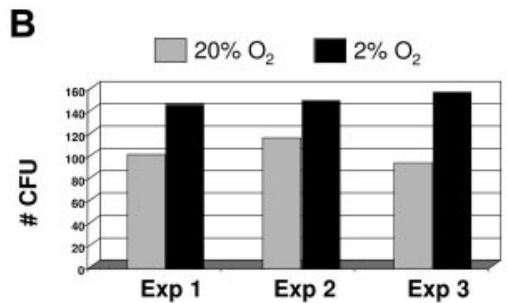

C
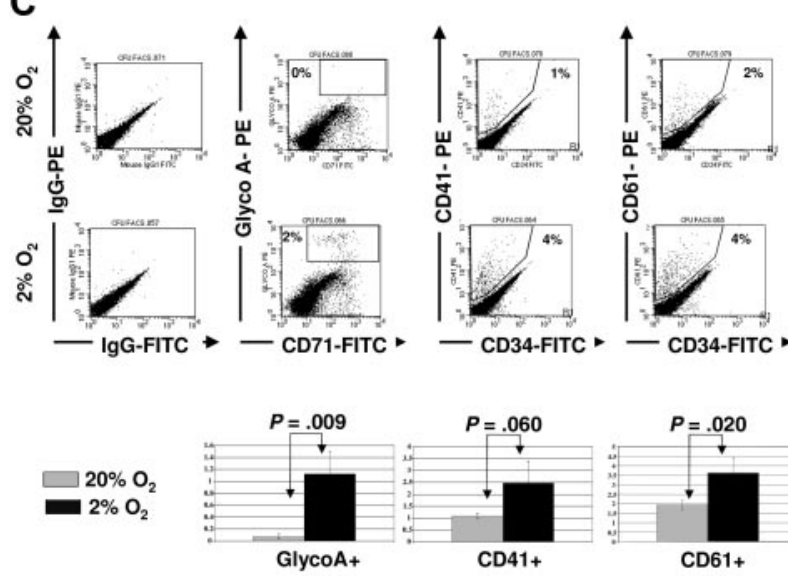

Figure 6. Surface phenotype of $\mathrm{CD}_{34}{ }^{+}$progenitors after 3-week culture in $2 \%$ to $3 \%$ versus $20 \% \mathrm{O}_{2}$ in osteoblastic-derived factors. $\mathrm{CD} 34^{+}$progenitors were plated on FN-coated plates in the presence of SCF, IL-6, and CXCL12 for 3 weeks, with half medium changes every 72 hours. (A) A representative phenotype of one experiment (above) and mean \pm SEM (below) of 3 independent cord blood experiments comparing $20 \%$ (gray) versus $2 \%$ to $3 \%$ (black) $\mathrm{O}_{2}$. (B) Cells recovered from the $20 \%$ (gray) and $2 \%$ to $3 \%$ (black) $\mathrm{O}_{2}$ cultures were plated in methylcellulose medium with complete cytokines, and scored after 12 to 14 days. (C) CFU colonies were harvested and labeled with antibodies against CD34, GlyA, CD41, and CD61. FACS plot of representative example is shown (above), as well as mean \pm SEM from 3 independent experiments (below).

A number of groups have already evaluated the effect of hypoxia on UCB-HPCs. Ivanovic et al have explored the possibility of using a $2 \%$ to $3 \% \mathrm{O}_{2}$ culture for ex vivo expansion of UCB-HPCs and noted a reduction in cell cycle kinetics but retention of $\mathrm{CFU}$ potential. ${ }^{42}$ Consistent with these reports, we observed a reduction in cell division kinetics and a higher percentage of $\mathrm{G}_{0}$ cells in $2 \%$ to $3 \% \mathrm{O}_{2}$ than in $20 \% \mathrm{O}_{2}$. The authors also noted a higher degree of cell death of UCB-HPCs in $2 \%$ to $3 \%$ $\mathrm{O}_{2}$ culture but that included IL-3-attenuated cell death. IL-3 is a cytokine produced by activated $\mathrm{T}$ cells, ${ }^{43}$ which are not the predominant cells within the bone endosteum. ${ }^{1}$ Furthermore, IL-3 promotes the commitment of HPCs to the myeloid lineage and acts as a survival factor for myeloid progenitors. ${ }^{44,45}$ It is therefore likely that the inclusion of IL-3 reduces cell death at $2 \% \mathrm{O}_{2}$ by increasing survival of more committed (eg, CD34 ${ }^{\mathrm{dim}}$ ) cells that develop during culture.

By contrast, we tested the factors thought to be present in the hypoxic HSC niche near the bone endosteum. Jung et al have demonstrated that the physical interaction between osteoblasts and HPCs promotes the survival of HPCs. ${ }^{13}$ Osteoblasts express VCAM-1, the ligand for the VLA-4 integrin, ${ }^{46}$ and secrete fibronectin, ${ }^{47}$ which has binding sites for the VLA-4 and VLA-5 integrins, both of which are present on HPCs. ${ }^{48}$ We demonstrate that engagement of the VLA-4 integrin UCB-HPCs by VCAM-1 and/or fibronectin activates a prosurvival signal in UCB-HPCs exposed to $2 \%$ to $3 \% \mathrm{O}_{2}$ that is associated with AKT phosphorylation, but not phosphorylation of MAPK.

Aside from its prominent role in cell survival, ${ }^{49} \mathrm{AKT}$ is the serine threonine kinase that phosphorylates GSK3 $\beta$ on Ser9, inactivating its activity. ${ }^{26}$ Inactive GSK3 $\beta$ loses its ability to promote the degradation of beta-catenin. ${ }^{50,51}$ Consistent with the increase in phospho-Ser473-AKT, we detected more phospho-Ser9GSK $3 \beta$ and more beta-catenin in UCB-HPCs cultured on FN at $2 \%$ to $3 \% \mathrm{O}_{2}$, compared with cultures in suspension. The change in beta-catenin is particularly interesting in the context of our current studies, as overexpression of beta-catenin in murine HSCs has been reported to increase their self-renewal and engraftment potential. ${ }^{30}$ However, changes in beta-catenin levels were confined to the cytoplasmic compartment, with no modulation in the nuclear beta-catenin detection level. Hence, it is unlikely that the greater $\mathrm{UCB}-\mathrm{CD} 34^{+}$progenitor engraftment potential following expansion under $2 \%$ to $3 \% \mathrm{O}_{2}$ conditions is simply due to hypoxia/ integrin-engagement mediated activation of the beta-catenin pathway, and other factors likely play a role.

In addition to the physical interaction between osteoblasts and HPCs, soluble factors secreted by the osteoblasts play an important role in the fate of HPCs. In preconditioned irradiated murine recipients, osteoblasts increase synthesis and secretion of CXCL12,39 a chemokine important in retention of endogenous HPCs within the niches, ${ }^{52}$ and in attracting transplanted HPCs to the BM niche. ${ }^{14,17}$ In addition, osteoblasts are the primary source of IL-6 and SCF in the bone endosteum. ${ }^{15,53}$ We hypothesized that a better representation of the in vivo preconditioned irradiated BM environment would be a combination of the OB factors CXCL12, IL-6, and SCF, and fibronectin. When UCB-CD34 ${ }^{+}$cells were cultured at $2 \%$ to $3 \% \mathrm{O}_{2}$ in the presence of these $\mathrm{OB}$ factors and $\mathrm{FN}$, levels of nuclear beta-catenin were elevated compared with cells maintained at $20 \%$ $\mathrm{O}_{2}$. This result is highly reminiscent of mechanisms underlying the regulation of self-renewal of intestinal stem cells where at least 2 signals are also required to promote nuclear beta-catenin localization and enhance its activity, ${ }^{54}$ namely the transient presence of Noggin combined with the inactivation of Pten, with, as a result, the activation of AKT. The nuclear localization of beta-catenin in our system is interesting and surprising as the nuclear translocation of beta-catenin is reported to result from Wnt proteins binding to Frizzled receptors. ${ }^{28}$ Throughout our studies, we omitted the use of fetal calf or human serum to rule out the interference of other factors present in serum; instead, we used a serum-substitute BIT-9500, which to date has not been reported to contain any Wnt proteins. Wnt proteins may also originate from nonhematopoietic cells such as fetal liver stroma, ${ }^{55}$ but none of our current experiments included the use of feeders, thus negating that possible 
source. Another potential source of Wnt proteins is HPCs themselves, which have been shown to secrete Wnt-5a. ${ }^{56}$ This last possibility deserves further investigation and might add to our understanding of how $\mathrm{UCB}$-derived $\mathrm{CD} 34^{+}$progenitors engraft in the bone endosteal environment.

$\mathrm{CD} 34^{+} \mathrm{CD} 38^{-}$cells, representing the more primitive subpopulation of $\mathrm{CD} 34^{+}$cells, ${ }^{57,58}$ could be readily detected following 7 days and 3 weeks of culture on fibronectin- and the osteoblastderived factors CXCL12, SCF, and IL-6 under hypoxic but not normoxic conditions. The importance of osteoblast-derived factors was confirmed further in cultures wherein $\mathrm{CD} 34^{+}$cells were cocultured with MG-63 cells, an osteoblast cell line known to express SCF, IL-6, and CXCL12. It should be noted that the percentage of $\mathrm{CD} 34^{+} \mathrm{CD} 38^{-}$was slightly but not significantly higher when $\mathrm{CD}_{3} 4^{+}$cells were maintained in the presence of FN and $\mathrm{OB}$ factors compared with the osteoblast cell line. It is possible that factors secreted by osteoblast cells in vitro yield a lower final concentration than when purified $\mathrm{OB}$ factors are added to the cultures, or are less efficient than recombinant exogenous factors until activated. For instance, SCF has been shown to be synthesized as a membrane-bound isoform and requires appropriate cleavage to exert maximal activity. ${ }^{59}$ Nevertheless, in general the effect of culture under hypoxia on FN with OB factors was highly similar to culture on the osteoblast cell line.

When cells from 3-week-old cultures were replated in standard 14-day CFU assays, significantly more CFU-GEMMs were detected in progeny of $2 \%$ to $3 \%$ than $20 \% \mathrm{O}_{2}$ cultures. FACS analysis of the secondary colonies demonstrated significantly more glycophorin A-positive erythroid cells, and $\mathrm{CD} 41^{+}$and $\mathrm{CD} 61^{+}$ megakaryocyte cells in progeny of hypoxic cultures with $\mathrm{OB}$ factors and on fibronectin. In earlier studies where UCB cells were cultured under $5 \% \mathrm{O}_{2}$, the concentration found in umbilical cord, greater numbers of BFU-Es and CFU-GEMMs were also noted, in comparison with controls maintained under $20 \% \mathrm{O}_{2}{ }^{40}$ Further- more, low oxygen culture has been shown to be favorable for maintenance of erythroid progenitors as well as megakaryocyte progenitors. ${ }^{60,61}$

We therefore conclude that although the $2 \%$ to $3 \% \mathrm{O}_{2}$ in the $\mathrm{BM}$ endosteum might be stress-inducing to UCB cells that originate from a more highly oxygenated ambience, the other BM microenvironmental components (ie, adhesion ligands and osteoblast-derived factors) can make the BM endosteum into a permissive environment for UCB-HPCs, maintaining both survival and possible self-renewal and multilineage differentiation properties.

\section{Acknowledgments}

This work was funded by grants 5F32CA103546-02 (M.A.D.), 2R01DK53041 (J.A.N.), and grant PO1-CA-65493 (C.M.V.) from the NIH.

We thank the St Louis University Cord Blood Bank staff for obtaining samples for this work.

\section{Authorship}

Contribution: M.A.D. designed and performed the experiments, analyzed data, and wrote the paper; M.H.C. provided cord blood for the research and proofed the paper; J.A.N. reviewed data, counted CFUs, helped with statistics, and proofed the paper; C.M.V. helped with the design of the research, reviewed data, and aided in writing the paper.

Conflict-of-interest disclosure: The authors declare no competing financial interests.

Correspondence: Catherine M. Verfaillie, Stamcel Instituut, Leuven, Katholieke Universiteit Leuven, Campus Gasthuisberg, Herestraat 49, 3000 Leuven, Belgium; e-mail: catherine. verfaillie@med.kuleuven.be.

\section{References}

1. Deldar A, Lewis $H$, Weiss L. Bone lining cells and hematopoiesis: an electron microscopic study of canine bone marrow. Anat Rec. 1985;213:187201.

2. Heissig B, Ohki Y, Sato Y, Rafii S, Werb Z, Hattori $\mathrm{K}$. A role for niches in hematopoietic cell development. Hematology. 2005; 10:247-253.

3. Islam A, Glomski C, Henderson ES. Bone lining (endosteal) cells and hematopoiesis: a light microscopic study of normal and pathologic human bone marrow in plastic-embedded sections. Anat Rec. 1990;227:300-306.

4. Kopp HG, Avecilla ST, Hooper AT, Rafii S. The bone marrow vascular niche: home of HSC differentiation and mobilization. Physiology (Bethesda). 2005;20:349-356.

5. Moore KA, Lemischka IR. Stem cells and their niches. Science. 2006;311:1880-1885.

6. Antoniou ES, Sund S, Homsi EN, Challenger LF, Rameshwar P. A theoretical simulation of hematopoietic stem cells during oxygen fluctuations: prediction of bone marrow responses during hemorrhagic shock. Shock. 2004;22:415-422.

7. Danet GH, Pan Y, Luongo JL, Bonnet DA, Simon MC. Expansion of human SCID-repopulating cells under hypoxic conditions. J Clin Invest. 2003;112:126-135.

8. Mendes SC, Robin C, Dzierzak E. Mesenchyma progenitor cells localize within hematopoietic sites throughout ontogeny. Development. 2005; 132:1127-1136.

9. Zhang J, Niu C, Ye L, et al. Identification of the haematopoietic stem cell niche and control of the niche size. Nature. 2003;425:836-841.

10. Calvi LM, Adams GB, Weibrecht KW, et al. Osteoblastic cells regulate the haematopoietic stem cell niche. Nature. 2003;425:841-846.

11. Kuznetsov SA, Riminucci M, Ziran N, et al. The interplay of osteogenesis and hematopoiesis: expression of a constitutively active PTH/PTHrP receptor in osteogenic cells perturbs the establishment of hematopoiesis in bone and of skeleta stem cells in the bone marrow. J Cell Biol. 2004; 167:1113-1122.

12. Visnjic D, Kalajzic Z, Rowe DW, Katavic V, Lorenzo J, Aguila HL. Hematopoiesis is severely altered in mice with an induced osteoblast deficiency. Blood. 2004;103:3258-3264.

13. Jung $Y$, Wang J, Havens A, et al. Cell-to-cell contact is critical for the survival of hematopoietic progenitor cells on osteoblasts. Cytokine. 2005; 32:155-162.

14. Jung $Y$, Wang J, Schneider A, et al. Regulation of SDF-1 (CXCL12) production by osteoblasts; a possible mechanism for stem cell homing. Bone. 2006;38:497-508.

15. Ishimi $\mathrm{Y}$, Miyaura $\mathrm{C}$, Jin $\mathrm{CH}$, et al. IL-6 is produced by osteoblasts and induces bone resorption. J Immunol. 1990;145:3297-3303.

16. Nodwell A, Carmichael L, Ross M, Richardson B Placental compared with umbilical cord blood to assess fetal blood gas and acid-base status. Obstet Gynecol. 2005;105:129-138.

17. Ceradini DJ, Kulkarni AR, Callaghan MJ, et al.
Progenitor cell trafficking is regulated by hypoxic gradients through HIF-1 induction of SDF-1. Nat Med. 2004;10:858-864.

18. Ivanovic Z, Belloc F, Faucher JL, Cipolleschi MG, Praloran V, Dello Sbarba P. Hypoxia maintains and interleukin-3 reduces the pre-colony-forming cell potential of dividing CD34(+) murine bone marrow cells. Exp Hematol. 2002;30:67-73.

19. Hermitte F, Brunet de la Grange P, Belloc F, Praloran V, Ivanovic Z. Very low O2 concentration $(0.1 \%)$ favors G0 return of dividing CD34+ cells. Stem Cells. 2006;24:65-73.

20. Mazurier F, Doedens M, Gan OI, Dick JE. Rapid myeloerythroid repopulation after intrafemoral transplantation of NOD-SCID mice reveals a new class of human stem cells. Nat Med. 2003;9:959963.

21. Wu MH, Smith SL, Danet GH, et al. Optimization of culture conditions to enhance transfection of human CD34 + cells by electroporation. Bone Marrow Transplant. 2001;27:1201-1209.

22. Cui L, Ramsfjell V, Borge OJ, Veiby OP, Lok S, Jacobsen SE. Thrombopoietin promotes adhesion of primitive human hemopoietic cells to fibronectin and vascular cell adhesion molecule-1: role of activation of very late antigen (VLA)-4 and VLA-5. J Immunol. 1997;159:1961-1969.

23. Risbud MV, Guttapalli A, Albert TJ, Shapiro IM Hypoxia activates MAPK activity in rat nucleus pulposus cells: regulation of integrin expression and cell survival. Spine. 2005;30:2503-2509.

24. Pinkse GG, Jiawan-Lalai R, Bruijn JA, de Heer E. RGD peptides confer survival to hepatocytes via 
the beta1-integrin-ILK-pAkt pathway. J Hepatol. 2005;42:87-93.

25. Torii S, Yamamoto T, Tsuchiya Y, Nishida E. ERK MAP kinase in G cell cycle progression and cancer. Cancer Sci. 2006;97:697-702.

26. Cross DA, Alessi DR, Cohen P, Andjelkovich M, Hemmings BA. Inhibition of glycogen synthase kinase- 3 by insulin mediated by protein kinase $B$. Nature. 1995;378:785-789.

27. Frame S, Cohen P, Biondi RM. A common phosphate binding site explains the unique substrate specificity of GSK3 and its inactivation by phosphorylation. Mol Cell. 2001;7:1321-1327.

28. van Noort M, Meeldijk J, van der Zee R, Destree $\mathrm{O}$, Clevers $\mathrm{H}$. Wnt signaling controls the phosphorylation status of beta-catenin. J Biol Chem. 2002;277:17901-17905.

29. Rubinfeld B, Albert I, Porfiri E, Fiol C, Munemitsu S, Polakis P. Binding of GSK3beta to the APCbeta-catenin complex and regulation of complex assembly. Science. 1996;272:1023-1026.

30. Reya T, Duncan AW, Ailles L, et al. A role for Wnt signalling in self-renewal of haematopoietic stem cells. Nature. 2003;423:409-414.

31. Willert K, Brown JD, Danenberg E, et al. Wnt proteins are lipid-modified and can act as stem cell growth factors. Nature. 2003;423:448-452.

32. Trowbridge JJ, Xenocostas A, Moon RT, Bhatia $M$. Glycogen synthase kinase- 3 is an in vivo regulator of hematopoietic stem cell repopulation. Nat Med. 2006;12:89-98.

33. Cole A, Frame S, Cohen P. Further evidence that the tyrosine phosphorylation of glycogen synthase kinase-3 (GSK3) in mammalian cells is an autophosphorylation event. Biochem J. 2004;377: 249-255.

34. Blair HC, Dong SS, Julian BA. Expression of stem cell factor by osteoblasts in normal and hyperparathyroid bone: relation to ectopic mast cell differentiation. Virchows Arch. 1999;435:50-57.

35. Wong GG, Witek-Giannotti J, Hewick RM, Clark SC, Ogawa M. Interleukin 6: identification as a hematopoietic colony-stimulating factor. Behring Inst Mitt. 1988;83:40-47.

36. Gao Z, Fackler MJ, Leung W, et al. Human CD34+ cell preparations contain over 100 -fold greater NOD/SCID mouse engrafting capacity than do CD34- cell preparations. Exp Hematol. 2001;29:910-921.

37. Civin $\mathrm{Cl}$, Strauss LC, Fackler MJ, Trischmann
TM, Wiley JM, Loken MR. Positive stem cell selection: basic science. Prog Clin Biol Res. 1990; 333:387-401 [discussion 402].

38. Bilbe G, Roberts E, Birch M, Evans DB. PCR phenotyping of cytokines, growth factors and their receptors and bone matrix proteins in human osteoblast-like cell lines. Bone. 1996;19:437-445.

39. Ponomaryov T, Peled A, Petit I, et al. Induction of the chemokine stromal-derived factor- 1 following DNA damage improves human stem cell function. J Clin Invest. 2000;106:1331-1339.

40. Smith S, Broxmeyer HE. The influence of oxygen tension on the long-term growth in vitro of haematopoietic progenitor cells from human cord blood. Br J Haematol. 1986;63:29-34.

41. Koller MR, Bender JG, Miller WM, Papoutsakis ET. Reduced oxygen tension increases hematopoiesis in long-term culture of human stem and progenitor cells from cord blood and bone marrow. Exp Hematol. 1992;20:264-270.

42. Ivanovic Z, Hermitte F, de la Grange PB, et al. Simultaneous maintenance of human cord blood SCID-repopulating cells and expansion of committed progenitors at low $\mathrm{O} 2$ concentration (3\%). Stem Cells. 2004;22:716-724

43. Schrader JW. The panspecific hemopoietin of activated T lymphocytes (interleukin-3). Annu Rev Immunol. 1986;4:205-230.

44. Du Y, Tsai S, Keller JR, Williams SC. Identification of an interleukin-3-regulated aldoketo reductase gene in myeloid cells which may function in autocrine regulation of myelopoiesis. J Biol Chem. 2000;275:6724-6732.

45. Antoku K, Liu Z, Johnson DE. IL-3 withdrawal activates a CrmA-insensitive poly(ADP-ribose) polymerase cleavage enzyme in factor-dependent myeloid progenitor cells. Leukemia. 1998;12:682689.

46. Tanaka Y, Morimoto I, Nakano Y, et al. Osteoblasts are regulated by the cellular adhesion through ICAM-1 and VCAM-1. J Bone Miner Res. 1995; 10:1462-1469.

47. Wrana JL, Maeno M, Hawrylyshyn B, Yao KL, Domenicucci C, Sodek J. Differential effects of transforming growth factor-beta on the synthesis of extracellular matrix proteins by normal fetal rat calvarial bone cell populations. J Cell Biol. 1988; 106:915-924.

48. Peled A, Kollet O, Ponomaryov T, et al. The chemokine SDF-1 activates the integrins LFA-1, VLA-4, and VLA- 5 on immature human CD34(+) cells: role in transendothelial/stromal migration and engraftment of NOD/SCID mice. Blood. 2000;95:3289-3296.

49. Vanhaesebroeck B, Alessi DR. The PI3K-PDK1 connection: more than just a road to PKB. Biochem J. 2000;346(pt 3):561-576.

50. Miller JR, Moon RT. Signal transduction through beta-catenin and specification of cell fate during embryogenesis. Genes Dev. 1996;10:2527-2539.

51. Orford K, Crockett C, Jensen JP, Weissman AM Byers SW. Serine phosphorylation-regulated ubiquitination and degradation of beta-catenin. J Biol Chem. 1997;272:24735-24738.

52. Levesque JP, Hendy J, Takamatsu Y, Simmons PJ, Bendall LJ. Disruption of the CXCR4/CXCL12 chemotactic interaction during hematopoietic stem cell mobilization induced by GCSF or cyclophosphamide. J Clin Invest. 2003;111:187-196.

53. van't Hof RJ, von Lindern M, Nijweide PJ, Beug H. Stem cell factor stimulates chicken osteoclast activity in vitro. Faseb J. 1997;11:287-293.

54. He XC, Zhang J, Tong WG, et al. BMP signaling inhibits intestinal stem cell self-renewal through suppression of Wnt-beta-catenin signaling. Nat Genet. 2004;36:1117-1121.

55. Martin MA, Bhatia M. Analysis of the human fetal liver hematopoietic microenvironment. Stem Cells Dev. 2005;14:493-504.

56. Van Den Berg DJ, Sharma AK, Bruno E, Hoffman $R$. Role of members of the Wnt gene family in human hematopoiesis. Blood. 1998;92:3189-3202.

57. Hao QL, Shah AJ, Thiemann FT, Smogorzewska EM, Crooks GM. A functional comparison of CD34 + CD38- cells in cord blood and bone marrow. Blood. 1995;86:3745-3753.

58. Petzer AL, Hogge DE, Landsdorp PM, Reid DS, Eaves CJ. Self-renewal of primitive human hematopoietic cells (long-term-culture-initiating cells) in vitro and their expansion in defined medium. Proc Natl Acad Sci U S A. 1996;93:1470-1474.

59. Longley BJ, Tyrrell L, Ma Y, et al. Chymase cleavage of stem cell factor yields a bioactive, soluble product. Proc Natl Acad Sci U S A. 1997;94:90179021.

60. Ono K, Alter BP. Effects of low oxygen tension and antioxidants on human erythropoiesis in vitro. Exp Hematol. 1995;23:1372-1377.

61. Katahira J, Mizoguchi H. Improvement of culture conditions for human megakaryocytic and pluripotent progenitor cells by low oxygen tension. Int J Cell Cloning. 1987;5:412-420. 